\title{
Perancangan dan Pembuatan Alat Scanner 3D Menggunakan Sensor Kinect Xbox 360
}

\author{
Arif Armansyah $^{1}$, Syarif Hidayatulloh ${ }^{2}$, Asti Herliana ${ }^{3}$ \\ ${ }^{1}$ Universitas BSI \\ e-mail: arifarma2501@bsi.ac.id \\ ${ }^{2}$ Universitas BSI \\ e-mail: syarif.sfq@bsi.ac.id \\ ${ }^{3}$ Universitas BSI \\ e-mail: asti.ala@bsi.ac.id
}

\begin{abstract}
Abstrak
Scanner 3D adalah teknologi yang digunakan untuk memindai objek nyata untuk mendapatkan bentuk, ukuran dan fitur lainnya agar menghasilkan gambar yang sangat akurat. Dalam perancangan alat scanner 3D sebelumnya, yaitu scanner 3D menggunakan sensor ultrasonik, infra merah, dan line laser. Maka dapat disimpulkan terdapat beberapa kekurangan yaitu masih terbatasnya objek yang di scan serta hasil scan yang belum akurat karena hanya menghasilkan garis-garis yang membentuk objek. Pada penelitian ini, penulis membuat scanner 3D dengan hasil akurasi yang tinggi. Scanner 3D yang dibuat adalah menggunakan sensor Kinect xbox 360. Cara kerja dari kinect yaitu dengan menggabungkan antara beberapa kamera, Color Cimos (VNA38209015) kamera ini berfungsi membantu dalam pengenalan objek dan fitur deteksi lainnya, serta kamera IR CMOS (VCA379C7130), dan IR Projector (OG12) yaitu sebagai depth sensor atau sensor kedalaman yang merupakan sebuah proyektor infrared dan sebuah sensor monochrome CMOS yang bekerja secara bersama-sama untuk melihat ruangan atau area dalam bentuk 3D tanpa memperdulikan kondisi cahaya. Untuk mengolah serta menampilkan hasil dari objek yang sudah di scan menggunakan aplikasi KScan3D. Kemudian untuk koneksi antara PC dengan media penggerak menggunakan Bluetooth HC-06. Setelah dilakukan pengujian didapatkan model gambar 3D dengan dengan hasil akurasi yang cukup tinggi.
\end{abstract}

Kata Kunci: Bluetooth HC-06, Infra Merah, Line Laser, Kinect, KScan3D, Scanner 3D, Ultrasonik

\begin{abstract}
Scanner $3 D$ is the technology used to scan real objects to get the form, size and other features in order to produce pictures that are very accurate. In the design of the appliance scanner $3 D$ previously, namely scanner 3D using the ultrasonic sensor, infrared and laser line. It can be concluded there are some disadvantages that is still limited objects in the scan and the scans are not accurate because only produces lines that formed the object. In this research, author make scanner 3D with high accuracy results. Scanner 3D is made using the XBOX 360 Kinect sensor. How to work from kinect namely with combining between some camera, Color Cimos (VNA38209015) this camera work help in the introduction of objects and other detection feature and IR camera CMOS (VCA379C7130), and IR Projector (OG12) as depth censorship or the depth sensor is a projector infrared and a monochrome sensor CMOS working together to see the room or area in the form of $3 D$ without neglecting the light conditions. To process and display the results from the object that is already in the scan using KScan3D application Then to the connection between the PC with media drives using Bluetooth HC-06. After the test is done obtained the model picture 3D with the results of the accuracy high enough.
\end{abstract}

Key Word: Bluetooth HC-06, Infra Merah, Line Laser, Kinect, KScan3D, Scanner 3D, Ultrasonik 


\section{Pendahuluan}

Sejarah perkembangan scanner berawal pada tahun 1975, ketika Ray Kurzweil dan timnya menciptakan Kurzweil Reading Machine beserta software Omni-Font Optical Character Recognation Technology. Software ini berfungsi mengenali teks yang ada dalam objek yang di scan dan menerjemahkannya menjadi data dalam bentuk teks. Dari awal perkembangan itulah teknologi scanner berawal dan akhirnya terus berkembang sampai saat ini dengan teknologi yang semakin lama semakin maju. Kini scanner sudah dapat digunakan untuk melakukan scanning objek tiga dimensi (Junaidi, Waslaluddin, \& Hasanah, 2015; Tarihoran, 2013; Purnama, 2012; Wanangsyah, Wurijanto, \& Sutanto, 2014)

Scanner 3D adalah teknologi yang digunakan untuk memindai objek nyata untuk mendapatkan bentuk, ukuran dan fitur lainnya agar menghasilkan gambar yang sangat akurat, serta memberikan informasi dari masing-masing objek pada layar komputer (Nair \& Thomas, 2016). Semua dimensi dari objek nyata dapat diambil, seperti panjang, lebar, tinggi, volume, fitur ukuran, fitur lokasi, luas permukaan, dan lainnya. Model dalam bentuk 3D inilah yang banyak digunakan secara luas diantaranya: Engineering Design, Manufacturing, Survey Technology, Engineering Construction, Arts, As Built Survey, Oil \& Gas Survey dan lainnya.

Penelitian sebelumnya, yang membahas mengenai scanner 3D terbatas pada pembahasan berupa jenis scannemya seperti scanner 3D menggunakan sensor ultrasonik, inframerah, dan line laser. Ketiga jenis sensor tersebut memiliki beberapa perbedaan dari segi hasilnya. Scanner yang menggunakan sensor ultrasonik memiliki kekurangan yaitu hanya dapat memindai benda silinder saja yang tidak terdapat banyak lekukan, seperti botol (Junaidi, Waslaluddin, \& Hasanah, 2015). Scanner yang menggunakan sensor inframerah memiliki hasil scan yang bergantung pada lokasi objek yang di scan, hasil scan akan tidak sesuai jika posisi objek kurang tepat (Nair \& Thomas, 2016). Scanner yang menggunakan sensor line laser memiliki kekurangan yaitu hasil yang didapat tidak memiliki tingkat keakurasian yang tinggi, hasil yang didapat masih berupa garis-garis yang membentuk pola objek (Lee \& Hoon, 2016). Permasalahan yang didapat dari penelitian sebelumnya terletak pada hasil scan yang belum akurat dan keterbatasan objek yang di scan tidak banyak.

Adanya permasalahan berupa kurang maksimalnya hasil serta keterbatasan objek yang di scan pada periode sebelumnya membuat penulis tertarik untuk membahas mengenai scanner 3D mengunakan sensor Kinect Xbox 360. Sensor kinect adalah alat input dengan teknologi software yang dikembangkan oleh Rare, sebuah perusahaan game dibawah Microsoft Game Studios milik Microsoft. Kinect digunakan untuk Video Game X Box 360 dan PC dengan sistem operasi Windows. Dulunya kinect ini diketahui adalah project Natal (Ayu, 2015). Kinect terdiri atas 3 kamera dan 4 mic-array, sehingga memungkinkan user untuk berinteraksi dengan game $\mathrm{Xbox}$ 360 tanpa menggunakan joystik (Xbox 360 Controller). Kinect akan mendeteksi seluruh gerakan tubuh user selama dalam jangkauan kamera Kinect yang jarak optimumnya antara 1.2 meter sampai 3.5 meter (Wanangsyah, Wurijanto, \& Sutanto, 2014). Lebih dari itu, Kinect sendiri mempunyai kelebihan yaitu sebagai scanner yang baik serta memiliki hasil scan yang lebih baik dari pada menggunakan sensor ultrasonik, inframerah, dan line laser. Hasil scan dari sensor kinect tersebut dapat digunakan untuk model karakter di dalam game, untuk membuat skenario digital secara virtual, serta hasil scan dapat digunakan untuk pencetakan 3D dan untuk manufaktur via mesin CNC Milling. Berdasarkan uraian diatas maka dirancang sebuah alat scanner 3D dengan memanfaatkan sensor Kinect XBOX 360 untuk menghasilkan gambar yang lebih baik dan akurat.

Perancangan dan pembuatan alat membutuhkan beberapa komponen yang mendukung sehingga alat tersebut berfungsi dengan baik ketika dioperasikan oleh pengguna. Adapun beberapa komponen yang dibutuhkan dalam perancangan dan pembuatan alat adalah sebagai berikut:

\section{Kinect Xbox 360}

Microsoft Xbox 360 Kinect atau biasa disebut Kinect, pada awalnya memiliki nama Project Natal. Kinect adalah produk dari Microsoft yang memperkenalkan teknologi motion gaming sebagai fitur utamanya. Kinect membuat pemain dapat berinteraksi dengan konsol Xbox 360 tanpa bantuan game controller. Menggunakan 
Kinect, pemain dapat bermain Xbox 360 cukup hanya dengan menggunakan gerakan anggota tubuhnya.

Teknologi Kinect diciptakan dengan tujuan untuk memperluas peminat konsol Xbox 360 diluar batas kalangan gamer. Saat ini Kinect bersaing ketat dengan Playstation Move milik Sony dan Wii MotionPlus milik Nintendo. Kinect pertama kali dirilis pada tanggal 4 November 2010 di wilayah USA.

Kinect dilengkapi dengan kamera RGB, Depth Sensor, Multi-Array Microphone untuk menangkap dan mengenali suara, dan dilengkapi sebuah Tilt motor agar bisa menyesuaikan derajat tangkapan kamera. Teknologi Depth Sensor Kinect merupakan sensor tiga dimensi (3D) untuk mengenali gerakan pemain. Sensor ini dapat mengenali sampai enam orang sekaligus, namun hanya dua pemain berstatus aktif yang dapat dideteksi gerakannya oleh Kinect. Depth Sensor terdiri dari sebuah proyektor Infra-Red (IR) yang dikombinasikan dengan sensor monokrom CMOS. Inilah yang dapat membuat Kinect melihat dalam bentuk 3D dalam keadaan cahaya apapun. Kalkulasi jarak antara obyek yang ditangkap dengan Kinect diperoleh berdasarkan sinar IR tersebut. Semakin pendek jaraknya, maka semakin bersinar poin yang ditangkap sensor. Jarak tangkap Depth Sensor dapat diatur. Kinect mampu mengkalibrasikan sensor secara otomatis berdasar pola permainan berada, termasuk benda-benda yang berada disekitar pemain.

Inovasi utama dari Kinect adalah kemampuannya yang lebih maju dalam mengenali wajah, gerakan dan suara. Kinect menghasilkan video dengan $30 \mathrm{~Hz}$ frame rate. Dengan video stream RGB pada VGA yang beresolusi 11-bit (640 x 480 pixel dengan tingkat sensivitas 2048). Sensor memiliki daerah pandang angular dengan sudut 57 derajat pada bidang horizontal dan 43 derajat pada bidang vertikal. Sensor ini juga dapat dimiringkan hingga 27 derajat ke atas ataupun ke bawah.

Kinect mampu menangkap dan mendeteksi gerakan tubuh secara akurat, pemain hanya menggunakan tubuh untuk berinteraksi dengan dashboard konsol Xbox 360 , bermain game, bahkan untuk mengakses fitur-fitur Xbox Live (Wanangsyah, Wurijanto, \& Sutanto, 2014).

\section{Mikrokontroler/interfacing}

Mikrokontroler adalah suatu chip berupa IC (Integrated Circuit) yang dapat menerima sinyal input, mengolahnya dan memberikan sinyal output sesuai dengan program yang diisikan kedalamnya. Sinyal input mikrokontroler berasal dari sensor yang merupakan informasi dari lingkungan sedangkan sinyal output ditujukan kepada aktuator dapat memberikan efek ke lingkungan. Jadi secara sederhana mikrokontroler dapat diibaratkan sebagai otak dari suatu perangkat atau produk yang mempu berinteraksi dengan lingkungan sekitarnya. Mikrokontroler pada dasarnya adalah computer dalam satu chip, yang di dalamnya terdapat mikroprosesor, memori, jalur Input/Output (I/O) dan perangkat pelengkap lainnya.

ATmega328 adalah mikrokontroler keluaran dari atmel yang mempunyai arsitektur RISC (Reduce Instruction Set Computer) yang dimana setiap proses eksekusi data lebih cepat dari pada arsitektur CISC (Completed Instruction Set Computer). Mikrokontroller ATmega328 memiliki arsitektur Harvard, yaitu memisahkan memori untuk kode program dan memori untuk data sehingga dapat memaksimalkan kerja dan parallelism. Instruksi-instruksi dalam memori program dieksekusi dalam satu alur tunggal, dimana pada saat satu instruksi dikerjakan instruksi berikutnya sudah diambil dari memori program. Konsep inilah yang memungkinkan instruksi-instruksi dapat dieksekusi dalam setiap satu siklus clock. $32 \times 8$-bit register serba guna digunakan untuk mendukung operasi pada $A L U$ (Arithmatic Logic unit) yang dapat dilakukan dalam satu siklus. 6 dari register serbaguna ini dapat digunakan sebagai 3 buah register pointer 16-bit pada mode pengalamatan tidak langsung untuk mengambil data pada ruang memori data. Ketiga register pointer 16-bit ini disebut dengan register $X$ (gabungan R26 dan R27), register $Y$ (gabungan R28 dan R29), dan register $Z$ (gabungan R30 dan R31). Hampir semua instruksi AVR memiliki format 16-bit. Setiap alamat memori program terdiri dari instruksi 16-bit atau 32-bit. Selain register serba guna di atas, terdapat register lain yang terpetakan dengan teknik memory mapped I/O selebar 64 byte. Beberapa register ini digunakan untuk fungsi khusus antara lain sebagai register control Timer/ Counter, Interupsi, ADC, USART, SPI, EEPROM, 
dan fungsi //O lainnya. Register-register ini menempati memori pada alamat $0 \times 20 \mathrm{~h}-$ 0x5Fh (Nebath, 2014).

\section{Motor DC}

Motor DC adalah motor listrik yang memerlukan suplai tegangan arus searah pada kumparan medan untuk diubah menjadi energi gerak mekanik. Kumparan medan pada motor dc disebut stator (bagian yang tidak berputar) dan kumparan jangkar disebut rotor (bagian yang berputar). Motor arus searah, sebagaimana namanya, menggunakan arus langsung yang tidak langsung/direct-unidirectional.

Keuntungan utama motor DC adalah sebagai pengendali kecepatan, yang tidak mempengaruhi kualitas pasokan daya (Purnama, 2012).

\section{Trust Bearing}

Bearing dalam bahasa Indonesia berarti bantalan. Dalam ilmu mekanika bearing adalah sebuah elemen mesin yang berfungsi untuk membatasi gerak relatif antara dua atau lebih komponen mesin agar selalu bergerak pada arah yang diinginkan. Bearing menjaga poros (shaft) agar selalu berputar terhadap sumbu porosnya, atau juga menjaga suatu komponen yang bergerak linier agar selalu berada pada jalurnya (Onny, 2012).

Acrylic

Acrylic atau akrilik adalah sebuah material yang mengandung bahan berasal dari asam akrilik atau senyawa sejenis. Bahan dasar dari pembuatan pipa atau tabung acrylic dan perabot material lainnya sendiri adalah dari Acrylic Polymethyl Methacrylate. Acrylic merupakan material plastik yang menyerupai kaca yang memiliki karakteristik yang transaparan atau tembus pandang dan memiliki sifat yang mudah cair bila dipanaskan (Amora, 2016).

\section{Bluetooth HC-06}

Bluetooth Modul HC-06 merupakan modul komunikasi nirkabel pada frekuensi 2.4GHz dengan default koneksi hanya sebagai SLAVE. Sangat mudah digunakan dengan mikrokontroler untuk membuat aplikasi wireless. Interface yang digunakan adalah serial RXD, TXD, VCC dan GND. Built in LED sebagai indikator koneksi bluetooth. Tegangan input antara 3.6- 6V, jangan menghubungkan dengan sumber daya lebih dari 7V. Arus saat unpaired sekitar $30 \mathrm{~mA}$, dan saat paired (terhubung) sebesar 10mA. 4 pin interface $3.3 \mathrm{~V}$ dapat langsung dihubungkan ke berbagai macam mikrokontroler (khusus Arduino, 8051, 8535, AVR, PIC, ARM, MSP430, dan lainlain). Jarak efektif jangkauan sebesar 10 meter, meskipun dapat mencapai lebih dari 10 meter, namun kualitas koneksi makin berkurang (Setiawan, 2015).

\section{Metode Penelitian}

Jenis penelitian adalah rancang bangun alat dengan menguji coba alat sistem scanner 3D menggunakan sensor Kinect. Keluaran dari alat ini adalah sinyal output dari sensor IR CMOS dan IR Projector yang akan memindai objek secara dengan hasil image tiga dimensi.

Adapun perancangan alat yang akan digunakan dalam penelitian ini adalah seperti gambar berikut :

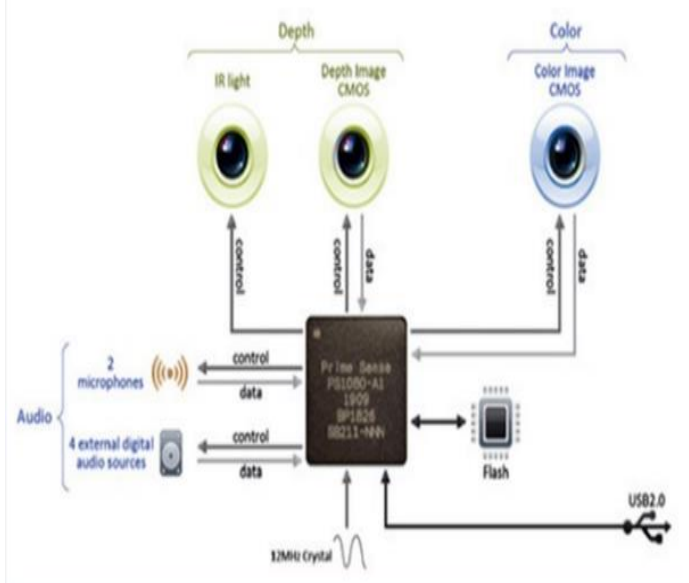

Gambar 1. Skema rancangan alat

Secara singkat prinsip kerja alat secara keseluruhan adalah sebagai berikut :

Cara kerjanya yaitu dengan menggabungkan antara beberapa kamera, Color Cimos, kamera ini berfungsi membantu dalam pengenalan objek dan fitur deteksi lainnya, serta kamera IR CMOS, dan IR Projector yaitu sebagai depth sensor atau sensor kedalaman yang merupakan sebuah proyektor infrared dengan metode ray Casting 3D Randing dan sebuah sensor monochrome CMOS yang bekerja secara bersama-sama untuk melihat ruangan atau area dalam bentuk 3D tanpa memperdulikan kondisi cahaya. Untuk mengolah serta menampilkan hasil dari objek yang sudah di scan menggunakan aplikasi KScan3D serta apabila objek tidak berhasil discan karena kesalahan pada software atau hardware makan akan ditampikan informasi error. 


\section{Hasil dan Pembahasan}

\subsection{Skema Alat}

Skema alat ini dibuat berdasarkan blok diagram kemudian dilanjutkan dengan pemilihan rangkaian yang tepat dan sesuai dengan alat yang akan dibuat sehingga pada akhirnya diperoleh hasil perancangan yang baik.

\begin{tabular}{|c|c|c|c|c|}
\hline Raw & Kamera & Depth Map & Ray Casting & KScan3D \\
\hline Depth & Tracking & Conversion & 3D Randing & \\
\hline
\end{tabular}

Gambar 2. Blok Diagram Kinect Xbox 360.

Input
Voice $\rightarrow \begin{gathered}\text { Bluetooth } \\ \text { HC-06 }\end{gathered} \rightarrow \begin{gathered}\text { ATmega } \\ 328 \mathrm{p}\end{gathered} \rightarrow \begin{gathered}\text { Hbridge } \\ \text { Driver }\end{gathered} \rightarrow \begin{aligned} & \text { Motor } \\ & \text { Wiper }\end{aligned}$

Gambar 3. Blok Diagram Penggerak Media

\subsection{Rangkaian Input} Kerja.

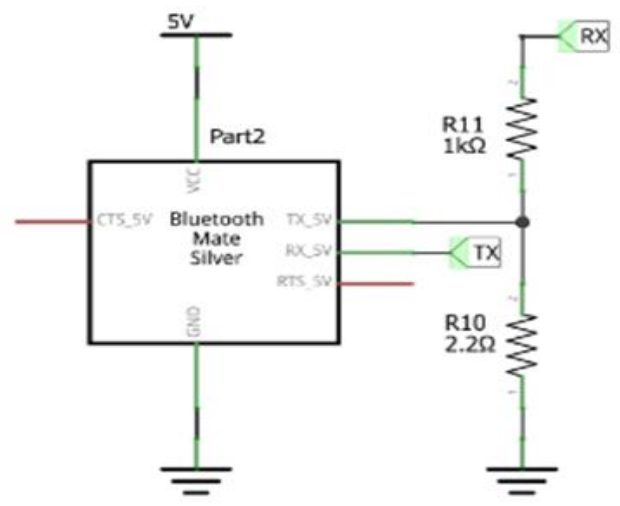

Gambar 4. Skema rangkaian Bluetooth.

Berikut ini adalah rangkaian input yang digunakan dalam perancangan dan pembuatan alat scanner 3D menggunakan sensor kinect xbox 360.

\subsection{Rangkaian Mikrokontroler}

Pada perancangan mikrokontroler penulis menggunakan IC ATmega328 sebagai pusat kontrol mulai dari input, proses dan output. Mikrokontroler ATmega328 merupakan mikrokontroler yang mempunyai arsitektur RISC (Reduce Instruction Set Computer) yang dimana setiap proses eksekusi data lebih cepat dari pada arsitektur CISC (Completed Instruction Set Computer). Mikrokontroler ini dipilih karena memiliki 14 pin I/O dua arah yang dapat digunakan untuk masukan dari Bluetooth, serta keluaran ke 5 volt. ATmega328 terdiri dari $1 \mathrm{~KB}$ memori EEPROM (Electrically Erasable Programmable Read Only Memory), data dapat dibaca dari memori apabila catu daya dimatikan, data terakhir yang ditulis pada memori EEPROM masih tersimpan pada memori (nonvolatile). Pada perancangan dan pembuatan penggerak media kerja pin yang digunakan adalah pin D0 (RX) dan D1 (TX) input dari Bluetooth, pin D5 (PWM), pin D6 (PWM) untuk driver wiper h-bridge, port D11 (PWM), D12, dan D13 untuk ISP, dan pin reset untuk mereset ulang kembali mikrokontroler ATmega 328 apabila program terjadi error.

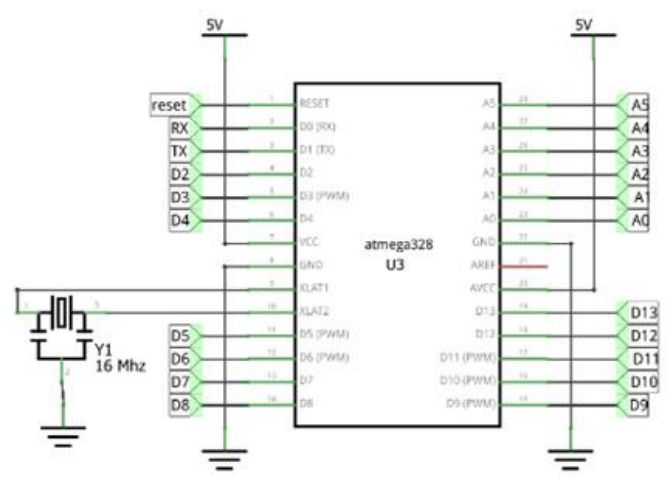

Gambar 5. Skema rangkaian mikrokontroler ATmega 328.

\subsection{Output}

Untuk driver motor DC penulis menggunakan sistem $H$-Bridge dengan menggunakan TIP 120 untuk NPN dan TIP 127 untuk PNP, tegangan yang dipergunakan sebesar 12V/5A untuk menggerakan motor $\mathrm{DC}$ wiper dengan daya $5 \mathrm{~A}$, karena untuk menggerakan motor DC wiper harus sesuai dengan driver-nya.

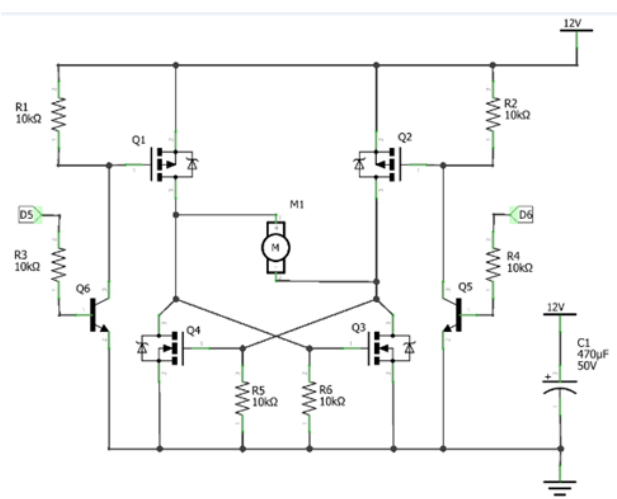

Gambar 6. Skema rangkaian Driver Wiper $\mathrm{H}$-Bridge.

\subsection{Rangkaian Catu Daya}

Rangkaian catu daya berfungsi untuk menurunkan tegangan $A C$ menjadi tegangan DC, dalam perancangan alat ini penuis menggunakan sumber catu daya yang berasal dari power supply PC. 


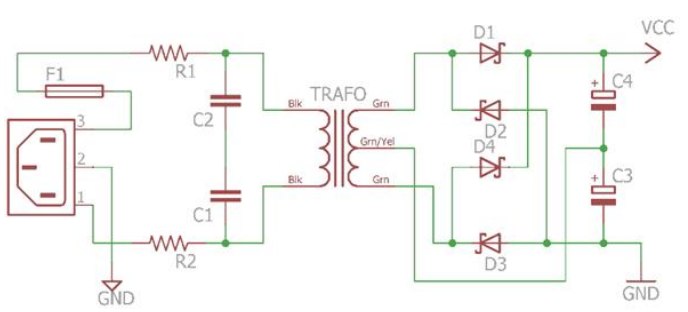

Gambar 7. Skema rangkaian Catu Daya.

\subsection{Rangkaian Keseluruhan}

Pada rangkaian keseluruhan akan ditampilkan mulai dari input, proses, dan output.

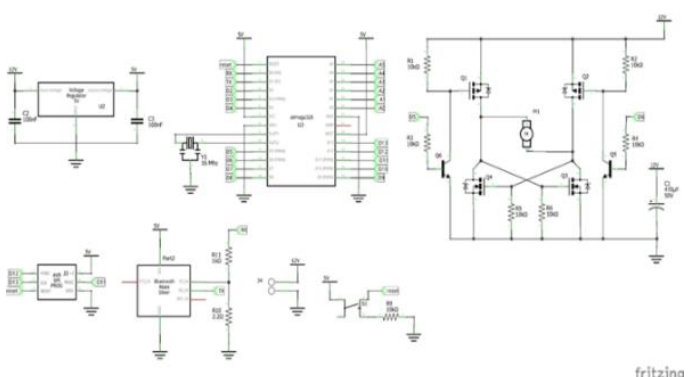

Gambar 8. Skema rangkaian keseluruhan.

\subsection{Rancang Program}

Pada rancang program ini akan dijelaskan penggunaan flowchart program scanner 3D.

\section{A. Flowchart Software}

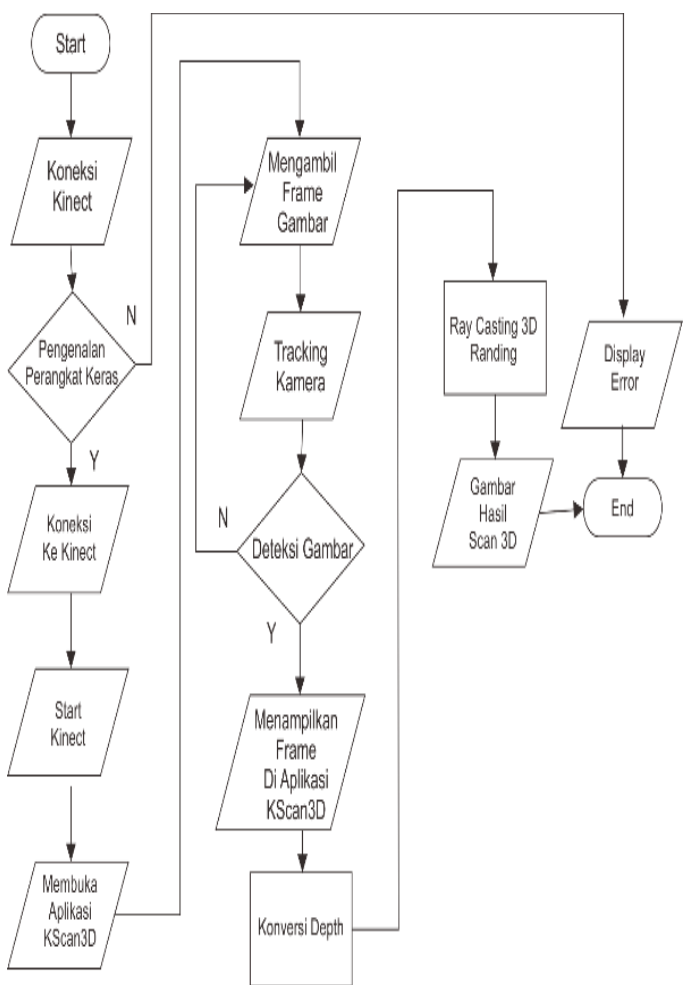

Gambar 9. Flowchart Software.

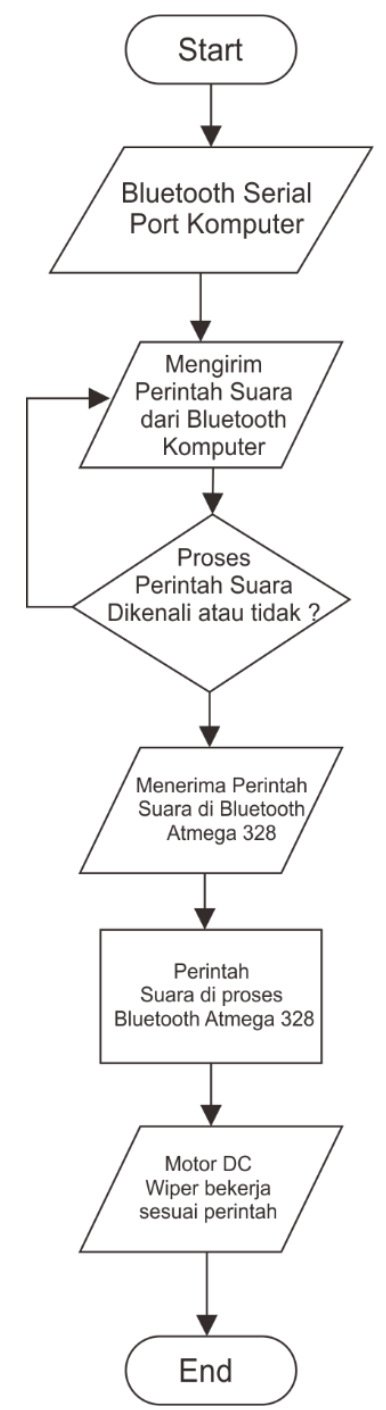

Gambar 10. Flowchart Hardware.

\subsection{PENGUJIAN DAN ANALISA}

\section{A. Tujuan Pengujian}

Pengujian alat ini digunakan untuk mengetahui kondisi alat dalam keadaan baik, memastikan sistem dari alat yang dibuat berjalan dengan benar sesuai perencanaan, mengetahui keluaran yang dihasilkan dari masing-masing rangkaian, baik rangkaian catu daya, input, proses maupun output.

\section{B. Langkah Pengujian}

Berikut ini adalah langkah pengujian untuk memeriksa kondisi alat scan 3D ini, adapun bagian-bagian yang perlu di uji yaitu:

1. Tegangan dari catu daya yang berasal dari adaptor dengan sumber tegangan $12 \mathrm{v}$ dan memiliki arus 5A. 
2. Pengujian jalur rangkaian pada mikrokontroler dengan menggunakan avo meter analog.

3. Pengujian koneksi aplikasi dengan kinect Xbox360.

4. Pengujian respon aplikasi Voice Recognition dengan mikrokontroler melalui koneksi Bluetooth.

\section{Pengujian Catu Daya}

Untuk tegangan DCV penulis menggunakan sumber tegangan dari power supply dengan sumber tegangan $12 \mathrm{v}$ dan arus 5Amp, tegangan tersebut dibagi dua yaitu untuk motor DC Wiper dan mikrokontroler. Untuk mikrokontroler penulis membatasinya dengan memberikan ic regulator $5 \mathrm{v}$ (LM7805) agar tegangan yang masuk tidak full $12 \mathrm{v}$ melainkan $5 \mathrm{v}$. Sedangkan untuk motor DC Wiper penulis menggunakan tegangan full $12 \mathrm{v}$. Berikut ini hasil pengujian catu daya.

Tabel 1. Tabel hasil pengujian catu daya.

\begin{tabular}{|c|c|c|c|c|}
\hline $\begin{array}{c}\text { Sumber } \\
\text { Tegang } \\
\text { an }\end{array}$ & $\begin{array}{c}\text { Output } \\
\text { Tegang } \\
\text { an }\end{array}$ & $\begin{array}{c}\text { Hasil } \\
\text { Penguku } \\
\text { ran }\end{array}$ & $\begin{array}{c}\text { Tegangan } \\
\text { Untuk } \\
\text { Bagian }\end{array}$ & $\begin{array}{c}\text { Has } \\
\text { il }\end{array}$ \\
\hline \multirow{2}{*}{ Adaptor } & $5 \mathrm{~V}$ & $5 \mathrm{~V}$ & $\begin{array}{c}\text { Mikrokontr } \\
\text { oler }\end{array}$ & $\begin{array}{c}\text { Bai } \\
\mathrm{k}\end{array}$ \\
\cline { 2 - 5 } & $12 \mathrm{~V}$ & $12 \mathrm{~V}$ & $\begin{array}{c}\text { Motor DC } \\
\text { Wiper }\end{array}$ & $\begin{array}{c}\text { Bai } \\
\mathrm{k}\end{array}$ \\
\hline
\end{tabular}

\section{Pengujian Input}

Untuk pengujian Input penulis melakukan dua pengujian input yaitu pengujian pada kinect $X b o \times 360$ dan pengujian pada media penggerak objek dengan suara. Untuk pengujian input kinect Xbox360 penulis melakukan koneksi antara usb kinect ke usb komputer maka di device manager akan terdeteksi beberapa hardware seperti pada gambar di bawah ini:

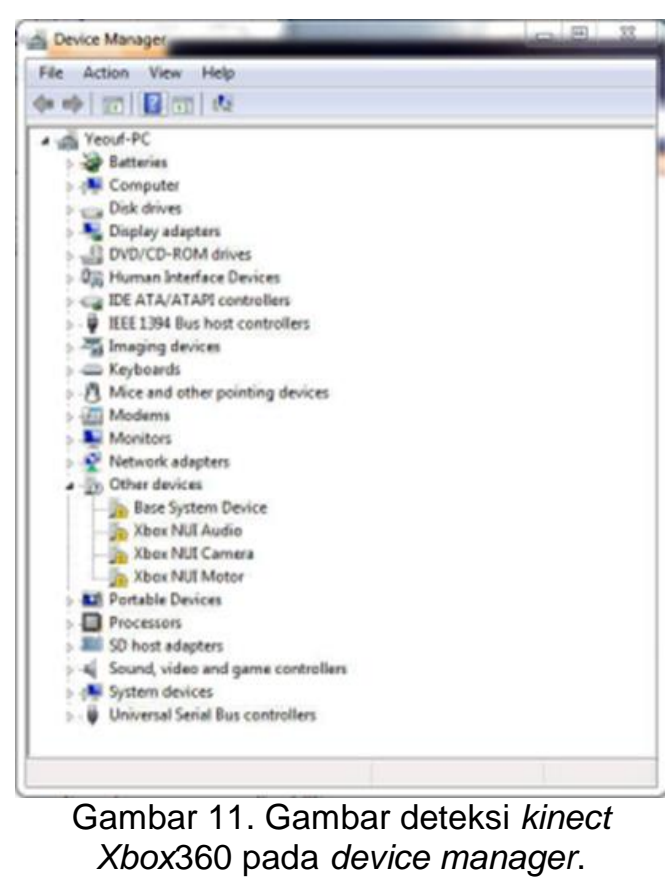

Pada device manager masih terdapat tanda seru itu disebabkan karena driver untuk kinect Xbox360 belum terinstalasi pada perangkat $\mathrm{pc}$ tersebut, setelah melakukan instalasi driver maka kinect Xbox360 bisa dipergunakan dengan aplikasi tambahan yaitu KScan3D. Dan untuk pengujian pada media penggerak objek yaitu dengan cara memberikan perintah suara melalui mic pada komputer agar perintah tersebut di eksekusi oleh mikrokontroler. berikut ini adalah perintahperintah yang bisa di eksekusi oleh mikrokontroler:

Tabel 2. Tabel Voice Recognition.

\begin{tabular}{|c|c|c|}
\hline Perintah Suara & $\begin{array}{c}\text { Fungsi } \\
\text { Perintah Suara }\end{array}$ & Status \\
\hline $\begin{array}{c}\text { Memulai proses } \\
\text { scan objek } \\
\text { Spin motor } \\
\text { faster } \\
\text { kerputar ke arah }\end{array}$ & $\begin{array}{c}\text { Memulai proses } \\
\text { scan objek } \\
\text { berputar ke arah } \\
\text { kiri }\end{array}$ & OK \\
\hline $\begin{array}{c}\text { Spin motor } \\
\text { slower }\end{array}$ & $\begin{array}{c}\text { Mempercepat } \\
\text { putaran motor } \\
\text { DC }\end{array}$ & OK \\
Turn motor off & $\begin{array}{c}\text { Perintah untuk } \\
\text { memberhentikan } \\
\text { putaran motor } \\
\text { DC }\end{array}$ & OK \\
\hline
\end{tabular}




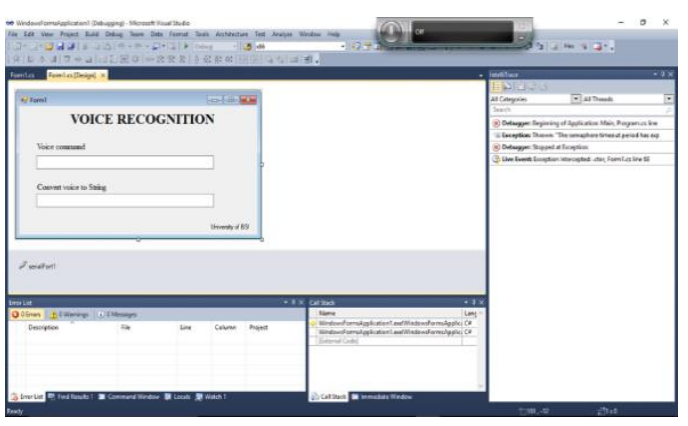

Gambar 12. Gambar tampilan voice recognition pada aplikasi visual studio.

\section{E. Pengujian Proses}

Untuk pengujian peroses pada kinect Xbox360 penulis melakukan scan objek menggunakan aplikasi KScan3D untuk menampilkan dan mengedit hasil scan objek sedangkan untuk media penggerak objek dengan menggunakan perintah "start kinecf' maka objek scan akan berputar kearah kiri dan kinect akan memulai proses scan dan menampilaknnya pada aplikasi KScan3D.

\section{F. Pengujian Output}

Untuk pengujian output pada kinect xbox360 yaitu dilakukan dengan cara melakukan proses scanning objek benda nyata sedangkan untuk pengujian output pada media penggerak yaitu akan bekerja jika media penggerak tersebut berputar dengan baik.

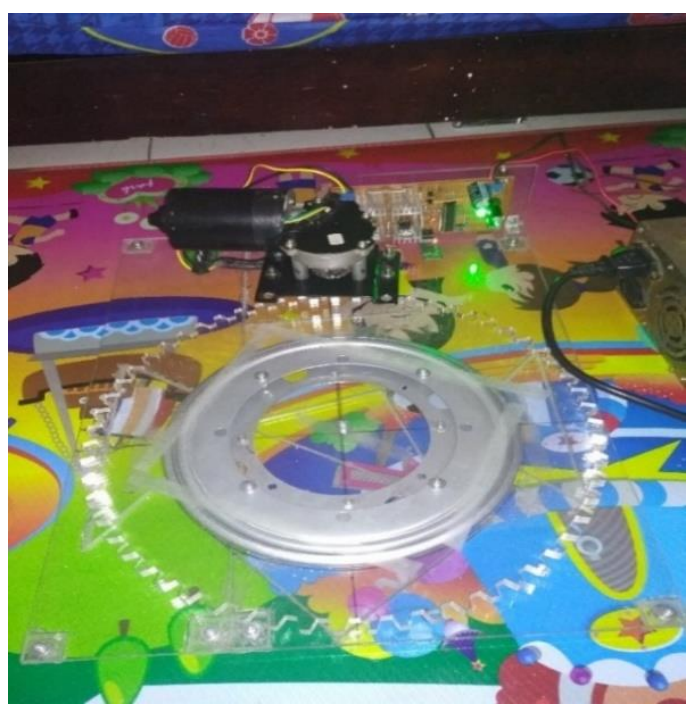

Gambar 13. Gambar media penggerak objek.

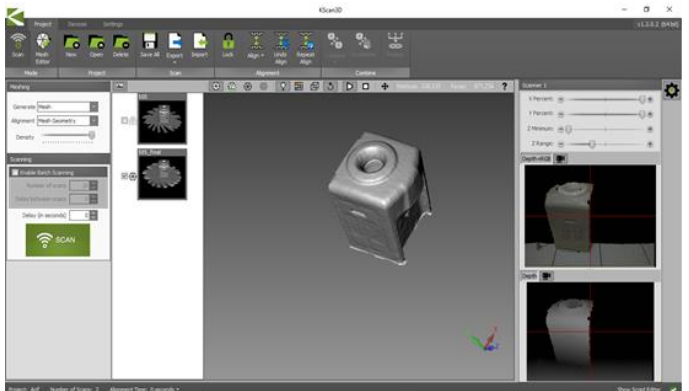

Gambar 14. Gambar hasil scan benda nyata.

\section{G. Hasil Scan Objek Benda Nyata} Menggunakan Kinect Xbox360
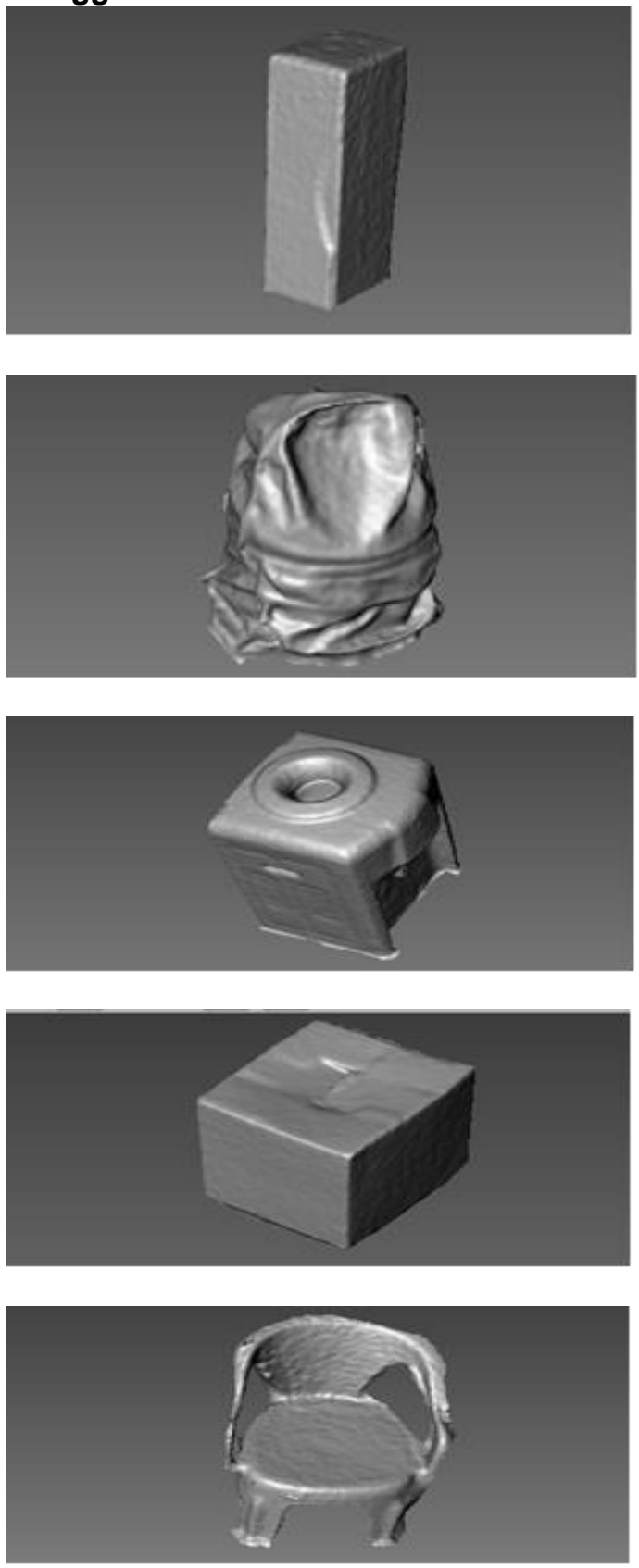

Gambar 15. Hasil Scan Scan Objek Benda Nyata Menggunakan Kinect Xbox360 


\section{Kesimpulan}

Berdasarkan uraian Perancangan alat scanner 3D dengan mengggunakan sensor kinect xbox360 dengan memanfaatkan sinyal output dari sensor IR CMOS dan IR Projector untuk memindai objek tiga dimensi ini, baik secara teoritis maupun penerapannya. Maka penulis dapat mengambil kesimpulan bahwa perancangan dan pembangunan alat scanner 3D menggunakan sensor Kinect xbox360 dapat memberikan kemudahan untuk para animator 3D dalam melakukan proses scanning karena hanya perlu mengedit hasil scan gambar dengan tingkat editing yang sedikit. Serta pada penelitian ini dibuktikan juga bahwa pemodelan objek nyata secara 3D memiliki akurasi yang tinggi, hal ini terlihat dari hasil penelitian yang dilakukan oleh penulis.

Dalam melakukan penelitian ini penulis menemukan beberapa masalah dan hambatan sehingga penulis menyadari bahwa dalam penelitian ini masih mempunyai banyak kekurangan yang diantaranya adalah teknik pembuatan 3D model menggunakan kinect bisa diteruskan dan dikembangkan dengan menggunakan aplikasi 3D lainnya tidak hanya terfokus pada aplikasi KScan3D. Penggunaan kinect seharusnya bisa dilakukan bukan hanya untuk 3D scanning saja tetapi bisa digunakan sebagai motion capture untuk animasi 3D serta objek yang dihasilkan masih belum sepenuhnya, karena kinect bukan dikhususkan untuk 3D scanning maka dari itu hasil masih dapat diperbaiki pada penelitian selanjutnya dengan menggunakan tools khusus 3D scanning. Lalu benda yang di scan memiliki kriteria yaitu tidak boleh benda yang bening atau transparan dan Jika ingin menghasilkan gambar yang lebih baik maka spesifikasi laptop/PC yang digunakan harus disesuaikan lagi dengan spesifikasi yang diberikan oleh kinect.

\section{Referensi}

Amora, R. (2016, Desember 13). Kegunaan Bahan Acrylic. Retrieved from Kaskus:

https://www.kaskus.co.id/thread/58 4fc3b6dcd770fc0a8b456a/kegunaa n-bahan-acrylic/

Ayu, T. (2015, April 18). Mengenal Kinect $X$ Box. Retrieved from Mengenal Kinect $X$ Box: http://triasayu.web.ugm.ac.id/2015/ 04/18/mengenal-kinect-x-box/

Junaidi, E., Waslaluddin, \& Hasanah, L. (2015). Rancang Bangun Scanner 3D Menggunakan Sensor Ultrasonik Dengan Tampilan Realtime Berbasis Mikrokontroler. Jurnal Online Fisika, 1-10.

Lee, k., \& Hoon, Y. (2016). Low-Cost Three-Dimensional Scanners Using Line-Laser and Maker Recognition for Rotation Angles. International Journal of Applied Engineering Research ISSN 0973-4562 Volume 11, 8234-8237.

Nair, A., \& Thomas, R. M. (2016). Infrared sensor based 3D image construction. International Research Journal of Engineering and Technology (IRJET), 24202424.

Nebath, E. (2014). Rancang Bangun Alat Pengukur Gas Berbahaya CO dan $\mathrm{CO} 2$ di Lingkungan Industri. $E$ Jurnal Teknik Elektro dan Komputer UNSRAT, 65-72.

Onny. (2012, mei 31). Pengertian Bearing. Retrieved from artikelteknologi.com: http://artikelteknologi.com/bearing/

Purnama, A. (2012, Juli 4). Retrieved from elektronika-dasar.web.id:

http://elektronika-

dasar.web.id/prinsip-kerja-motordc/

Setiawan, E. T. (2015). PENGENDALIAN LAMPU RUMAH BERBASIS MIKRONTROLER ARDUINO MENGGUNAKAN SMARTPHONE ANDROID. Jurnal TI-Atma STMIK Atma Luhur Pangkalpinang, 1-8.

Tarihoran, P. (2013). Sejarah Scanner. Computer Science.

Wanangsyah, W., Wurijanto, T., \& Sutanto, T. (2014). Aplikasi Virtual Punch Training Menggunakan Microsoft Xbox Kinect. JSIKA Vol. 3, No. 1, 94-101. 